\title{
The Challenge of Information and Communications Technology in Education
}

\author{
Peter Ilic $^{1 *}$ \\ ${ }^{1}$ Center for Language Research Sciences, University of Aizu, Aizu-wakamatsu, Japan
}

\begin{abstract}
The dramatic impact of Information and Communications Technology (ICT) on society suggests the potential for an analogous effect on education. The prospects for some benefit from the affordances offered by ICT are appealing but not entirely understood by many educators. The challenges of design, implementation, assessment, and analysis of ICT supported education are considerable. These challenges include how ICT can support traditional learning approaches, add new educational opportunities, and reduce resistance to introducing disruptive technologies such as smartphones. The affordances of ICT in education open many possibilities to integrate with and support existing curriculums. However, many educational institutions have not fully embraced these opportunities. This paper will explore some barriers to ICT adoption in the educational context. The first section is a brief introduction followed by a section on the history of educational theory to illustrate the considerable body of knowledge available on this topic. The third section introduces a type of case study of the challenges faced by a nation in providing the infrastructure needed to implement many of these technologies. Section four gives a summary of many, but not all, barriers to technology adoption faced by educational administrators, instructional designers, educators, and learners. And the final section is a brief conclusion.
\end{abstract}

\section{Introduction}

The dramatic impact of ICT on society suggests the potential for an analogous effect on education. The prospects for some benefit from the affordances offered by ICT are appealing but not entirely understood by many educators. The challenges of design, implementation, assessment, and analysis of ICT supported education are considerable. These challenges include how ICT can support traditional learning approaches, add new educational opportunities, and reduce resistance to introducing disruptive technologies such as smartphones. The affordances of ICT in education open many possibilities to integrate with and support existing curriculums. However, many educational institutions have not fully embraced these opportunities. The educational field is characterized by training teachers to use specific online tools, but a clear understanding of the theory informing the use of these tools to transform our educational practice is often overlooked. Theories always change more rapidly than practice, so when a new cognitive theory is developed to compensate for a previous one's inadequacy, there is an inevitable lag in adoption by instructional designers [1]. This may be one reason that, rather than transforming pedagogy through the affordances of new technologies, it is a common tendency of educators to merely integrate technology into traditional behaviorist ways of teaching. For example, many institutions' learner management systems (LMS) are mainly used for standard administrative purposes, to distribute resources or information, and to complement or replicate traditional educational practices. This paper will discuss some factors that inhibit educators from exploiting the broad range of affordances offered by ICT.

\section{Educational theory and ICT}

At the level of theory, education can be divided into three major theoretical frameworks: behaviorism, cognitivism,

\footnotetext{
* Corresponding author: pilic@u-aizu.ac.jp
} 
Constructivism, Connectivism. In the early $20^{\text {th }}$ century, behaviorism developed from the work of several researchers as a counterargument to the Freudian emphasis on the unconscious mind within an environment dominated by positivism and the rise of the scientific method. As positivists, they viewed the mind as inaccessible and therefore irrelevant, a black box, for study. In simple terms, behaviorist learning theory emphasizes two major types of conditioning relationships between environmental stimulus and observed response. First, Pavlov's classical conditioning [2], learning is a visible change in one's behavior manifested in a reflex reaction on an associated environmental stimulus. The second, Skinner's operant conditioning [3], in which there is reinforced learning of new behaviors, not just reflexes. Also, complex behaviors are learned through more simple ones, and different reinforcement intervals have different effects. The rise of behaviorism coincided with mechanization in the labor force and demands for an increasingly educated population through compulsory education. Industrialization required workers who could read, write, and perform tasks repeatedly and reliably. This theory fits well to instructional design based on specific and discrete learning steps and mechanization of this process through new forms of learning technologies. Behaviorist learning technology started as teaching machines [4] that resembled typewriters and used paper slips to record answers. Skinner expanded on these ideas to develop programmed instruction [5], where self-instruction of the content was linked with self-testing.

Both technologies were mainly focused on hardware rather than on content. In the 1950s, computer-assisted instruction (CAI) was developed using a drill-and-practice approach to learning. Due to the complexity and high cost of computers at that time, the programmer had most control over the content and there was initially a lack of quality software. The US Department of Defense became a major funder of CAI and developed two of the early systems [6]: Programmed Logic for Automated Teaching Operations (PLATO) with the University of Illinois and Time-shared Interactive Computer-controlled Television (TICCIT) with the University of Texas. The military reported a reduction in learning time from $24 \%$ to $54 \%$. Many techniques developed from these programs influenced $\mathrm{K}-12$ and university education. Also, as the personal computer became more common in the 1980s, CAI flourished. However, behaviorism does not explain all learning since it ignores internal factors such as emotion, motivation, and learner's subjective environment and learning history. Today, behaviorism has lost much influence and was replaced by cognitivism as the dominant learning paradigm.

Cognitivism emerged as a reaction to behaviorist theory, but it did not reject behaviorist science altogether, so aspects of the older theory survive in newer theory. Cognitivist learning theory was a response to behaviorism's rigid emphasis on the direct link between stimulus and response.
Cognitivist psychologists argued that the link between stimulus and response was not straightforward and that there were several other factors involved [1]. The emphasis was shifted from external behavior to internal mental processes with the goal of understanding how cognitive processes could promote effective learning. The learner was no longer seen as a passive participant, and the black box was opened to explain complex cognitive processes and architecture. The learner's prior knowledge was now considered, the concepts of stimulus and response were reshaped into input and output, and learning was now associated with information processing, memory, perception. Since memory has a crucial role in acquiring and retaining knowledge, it was an essential part of many cognitivist learning theories. The cognitivism paradigm led to several influential learning theories, including cognitive information processing [7], which views the brain as a type of computer. Other influential work included Schema Theory [8] and Gagne's conditions of learning [9], which bridged the gap between behaviorism and cognitivism. Social Cognitive Learning Theory [10], unlike behaviorism, emphasizes that the environment and cognitive factors influence behavior. These learning theories and others led to many changes in instructional design that included Concept Mapping [11], Component Display Theory [12], and Structural Learning Theory [13].

However, throughout its history, critics of cognitivism have questioned its assumption that mental functions can be compared to an information processing model [14]. In CAI, the computer evaluates the learner's response with appropriate feedback and then branches the learner into either moving ahead or to a review. This branching action is designed by the programmer and is a behaviorist form of instructional design. As computer technology advanced, these branching programs became more complex and eventually led to the development of Intelligent Tutoring Systems (ITS). Whereas CAI is content-free, ITS are much more complex and based on specific knowledge domains taught to the individual students by the computerized tutor. Since relatively few ITS systems have been introduced to schools, they have been criticized for promising too much and being too restrictive [15].

The term Constructivism refers both to a learning theory and to an epistemology of learning, and the term Constructivist refers to only the learning theory. Both are generally distinct from behaviorism and cognitivist theories of learning. In the 20th century, the major theorists associated with Constructivist approaches were Jean Piaget and Lev Semyonovich Vygotsky. There are two major perspectives associated with Constructivism: Cognitive Constructivism and Social Constructivism. Piaget's Cognitive Constructivism [16] says that a learner's understanding of the world grows by going through linear biological developmental stages, so there is a focus on the individual learner. Vygotsky's Social Constructivism [17] says that meanings and understandings grow out of social 
encounters, so it is focused on the social essence of knowledge construction.

Constructivist theory suggests that people construct their own understanding and knowledge of the world through experiencing the world and then reflecting on those experiences. When people encounter new ideas, new things, and new perspectives, they must reconcile the new with prior understanding. If the new does not fit with previous understanding, the person must decide to discard it, integrate it with existing views, or change existing beliefs. This is an active process of asking questions, exploring, engaging in dialogue with others, and reassessing what we know, so this is what is meant by actively creating and constructing one's knowledge. In this approach, knowledge cannot be transferred directly to the learner, but instead is constructed by the learner by constructing a subjective interpretation and subjective meaning of the objective reality. So, learning occurs through the interaction of the learner's prior knowledge, ideas, and experience while in social, cultural, and linguistic settings. Some influential learning theories that emerged from this paradigm include Communities of Practice [18], Discovery Learning [19], Case-Based Learning [20], and Simulation-Based Learning [21].

The learning technologies associated with Constructivism are often called learning environments or microworlds, and they are usually computer-based software that is open-ended to enable and require active user input. These learning environments try to represent the natural complexity of the real world, emphasize knowledge construction instead of knowledge reproduction, emphasize authentic tasks in a meaningful context, avoid predetermined sequences of instruction, and support collaborative construction of knowledge through non-competitive social negotiation [22]. Computers are an efficient medium for applying Constructivist principles to educational practice because computer software can support various strategies and approaches more efficiently and effectively than other media. Technological implementations of this theory have succeeded and include educational programming language Logo [23], Apple Hyper-Card software [24], and York University's computer-supported intentional learning environment (CSILE) [25].

Introduced in 2004 by George Siemens, Connectivism [26] is a learning paradigm that considers the technological developments during the last few decades, such as chaos theory, self-organization, and networks. Connectivism was initially based on a concept of self-organized learning but evolved to emphasize network-organized learning. The idea is that a networked environment without instructors and course structure can facilitate learning. So, learning is based on the notion of network intelligence, in which the computer network independent of humans controls the links for each learner. Even though Connectivism is a theory, little empirical evidence has accumulated to confirm it. Learning is defined as actionable knowledge that can reside in a person or outside one in a database or organization. The learning process is focused on connecting information sources and maintaining those connections because the body of knowledge is rapidly changing, so knowledge transferred to students becomes less efficient over time. It is criticized for being more a pedagogical approach or a model rather than a learning theory because it does not attempt to explain processes of learning. It also describes learning as actionable knowledge emphasizing only the result, not the process of learning [27].

\section{ICT in Japan}

These issues are not unique to any one country, but a closer look at Japan's approach to ICT in education may be informative. In 1985 the First Report of the National Council on Educational Reform [28] noted the increasing significance of ICT in Japanese Education. In this report, this "informatization of education" consisted of three elements: children's information literacy, utilization of ICT in course instruction, and utilization of ICT in school administrative works. In the 1986 Second Report of the National Council on Educational Reform [29], the qualities that enable individuals to utilize information and information media were added to the existing core subjects of reading, writing, and arithmetic. In 1987, the Report of the Curriculum Council led to the introduction of the 1989 introduction of a new elective subject "basic information" into technology and home economics classes at lower secondary schools. Then the 1998 Report on the curriculum Council led to designating the subject "information and computer" in technology and home economics classes at lower secondary schools as a compulsory subject and established a new compulsory subject "information" for general education courses at upper secondary schools.

The 2001 Basic Act on the Formation of an Advanced Information and Telecommunications Network Society [30]included consideration of the urgent need to keep pace with the rapid and drastic changes on a global scale arising from ICT through introducing measures for the formation of an advanced information and telecommunications network society. Towards this goal, the act called for developing strategies, determining local and governmental responsibilities, the establishment of a strategic headquarters for the promotion of an advanced information and telecommunications network society, and developing a priority policy program. The 2001 act helped to establish several national strategies about ICT in education. The first was the 2001 e-Japan strategy I [31], which was focused on network infrastructure and aimed for Japan to become the most developed country in the world in ICT. By the end of 2003 , high-speed internet access was available to $60.6 \%$ of the population. The second strategy came in 2003, the $e$ Japan strategy II [32] focused on socio-economic structures 
with an emphasis on the use and applications. By the end of 2003, e-Government Electric filing of Government of Japan was $96 \%$, and e-Commerce Internet Trade (Stock Market) was $23 \%$ of all exchanges. The final strategy from the 2001 act was the $2004 u$-Japan Initiative [33], which focused on developing a ubiquitous network society. The 4 U's of this strategy included, ubiquitous (anywhere, anytime, anyone, anything), universal (networks are comfortable to use by people), user-oriented (needs of the user), and unique (vitalizing society and business).

In 2008, the Report of the Central Council for Education called for cross-curricular improvements for coping with social conditions concerning the ICT environment and the importance of information education. However, this ICT development did not filter down to the life of the average citizen. The cause for this was identified as a past emphasis on the use of digital technologies, a prioritization of technology, and an excessive emphasis on the perspective of manufacturers and service providers [34]. Then, in 2009, $i$ Japan Strategy 2015: Towards Digital inclusion \& innovation [34] was launched and shifted the focus from technology to create a digital society where all citizens can accept human-centric digital technologies developed from the perspective of citizens. This strategy's goals included developing easy-to-use digital technologies, breaking down barriers to using digital technology, ensuring security when using digital technologies, and creating a "New Japan" where Digital Technologies and Information are diffused throughout the economy and society. Many of the goals leveraged ICT's well-known affordances, including rapid feedback, active knowledge-making, differentiated learning, and ubiquitous learning. The 2011 report entitled The Vision for ICT in Education [35] went even further to focus on the affordances and stated that ICT is very important but nothing more than a tool with potential limitations. The report lists many potential uses and affordances of ICT in education.

Despite these initiatives, in 2009, Japan was still seen as lagging behind other peer countries in the transition to an information-based society[36, 37]. Japanese universities have received the majority of the blame for these results for several reasons, including a low adoption rate for ICT tools such as learning management systems and a reported lack of staff to produce digital content [38]. Funamori [38] detailed several possible reasons for this lag. First, Japan failed to understand that computers were becoming communication tools rather than computational tools. Then, in general, teachers avoid using ICT tools to share information with and communicate with students. Third, a widespread belief that prolonged usage of ICT will harm students' human nature led to the widespread banning of mobile phones in the classroom. Finally, even though most people now appreciate the benefits of ICT tools, they are still viewed as being in the same category as basic infrastructure utilities.

\section{Barriers to ICT}

When we consider the considerable theoretical work completed, it may surprise some as to how little has changed in most educational institutions. The main learning activities on the LMS are posting content-based resources such as web pages and lecture notes, collecting assessments from students through digital versions of traditional assessment methods [38]. While these activities aid instructors in the administration of classes, activities that demand student collaboration or reflection are used less frequently than those that replicate face-to-face teaching modes [38, 39].

The relatively stable traditional classroom learning context includes common resources, consistent schedule and location, and a single instructor with an agreed curriculum [40]. So, when technology is incorporated, it is essential that it does not create a completely separate space but adds to the continuum of learning [41] and bridges the moments of learning [42]. Here a key factor is how well the design of the system allows for quick integration with a minimal learning curve. In terms of Human Computer Interface (HCI) design, Distributed Cognition (DCog) is an influential framework which attempts to describe knowledge as being distributed across objects individuals, artifacts, and tools in the environment[43]. DCog analyses the interactions between these distributed units to better understand how they are coordinated and to examine the cognitive properties of HCI design.

Learning analytics provides feedback based on the analysis of learner data, which are believed to have beneficial effects on both learning and the learning environment [44]. However, there is the added concern of the laws controlling information used on these systems [45]. Applying learning analytics interventions in practice on the different actors, processes, and outcomes involved is a complex task requiring expertise in data collection, data analysis, and relevant course content knowledge [46]. For example, testing on mobile devices is a similar issue since, without on-site supervision, teachers have little reason to trust that the student will participate honestly. Also, learning outcomes, such as Constructivist self-regulated learning skills, are challenging to measure, so learning analytics should move away from mere performance-based evaluation of learning analytics projects and include measurements related to learning processes and learning environment [47]. The effects of learning analytics on learning must be defined [47] as often the measured learning proxies, such as grades and LMS activity, can be overly narrow and miss much like student activity outside of school [48]. Instead, an approach including assessment from multiple perspectives, such as a peers, self, teacher, parents, invited experts, and machine feedback can help provide a clearer picture of student learning.

Stakeholder confidence with technology was linked to better computer-integration [49], but teachers that lack this 
confidence [50-55] have had the opposite effect. An issue that frequently appears in the literature is lack of skilled personnel [38, 52, 56-59], technology support, and material development available in the educational institution, which can have broad-ranging effects on decisions to adopt ICT. There is also a widespread lack of awareness $[52,54]$ of the educational affordances offered by ICT. Also, there is there are always some administrators or teachers that lack of motivation $[56,60,61]$ to invest the considerable effort required to integrate ICT. Some teachers hold strong negative attitudes $[50,51]$ to including ICT because the devices are not immediately associated with education [62]. A frequently cited issue is that the mobile context afforded by ICT increases the chance for distraction [63] while making it more difficult for teachers to follow up on learning achievements. Also, educators mention the lack of class time $[57,64]$ outside of regular responsibilities needed to integrate technology into the existing curriculum $[58,65$, $66]$.

At the administrative level, a lack of funding [53, 57, 6769] often leads to poor ICT infrastructure [52, 55, 58, 66, 7074] which is another barrier teachers cannot overcome on their own. This can also cause low connectivity rates that make many of the ICT approaches $[52,57,66,70]$ impractical. Even if there is a robust infrastructure in place, the lack of software tools [67] or the lack of devices [59] to run those tools are more barriers to adoption. It is important to remember that the adoption of mobile technology is no guarantee of the adoption of mobile services [75] and vice versa. Administration is also aware of risk involved with the adoption of any new educational system, such as security risks. In a 2014 study, Japan ranked $12^{\text {th }}$ on relative risk aversion out of 25 developed countries [76]. For this the institution must develop a risk profile of the most likely risks it will face and how much is acceptable. This assessment should include both the risk of adopting the new technology and the risk of not adopting it [77].

\section{Conclusion}

This paper has attempted to provide an overview of ICT in education. It is not meant to be an exhaustive discussion on all issues related to this topic. A brief history of the theory driving ICT adoption in education was provided because many educators and administrators making decisions on the adoption of technologies in schools may be unfamiliar with the key paradigms. Also included are the major steps taken by Japan to rapidly build its infrastructure and educate its citizens to use it. This may help clarify the challenges faced by countries all over the world. The considerable variety of factors that act as barriers to the adoption of ICT in schools included here make it clear that this is a multivariate issue that requires powerful analysis methods to measure and understand. Future research will attempt to better understand the interrelationship between these factors to better inform the stakeholders' decisions.

\section{REFERENCES}

[1] W. Winn, "Cognitive perspectives in psychology," Handbook of research for educational communications and technology: A project of the Association for Educational Communications and Technology, D. H. Jonassen and M. Driscoll, eds., pp. 79-112, New York: Taylor \& Francis, (2004).

[2] I. P. Pavlov, "The Scientific Investigation of the Psychical Faculties or Processes in the Higher Animals," Science, 24, no. 620, pp. 613-619, (1906).

[3] B. F. Skinner, "Operant behavior," American psychologist, 18, no. 8, pp. 503-515, (1963).

[4] S. L. Pressey, "A machine for automatic teaching of drill material," School \& Society, 25, pp. 549552, (1927).

[5] B. F. Skinner, "Review Lecture-The technology of teaching," Proceedings of the Royal Society of London. Series B. Biological Sciences, 162, no. 989, pp. 427-443, (1965).

[6] J. Fletcher, "Education and training technology in the military," science, 323, no. 5910, pp. 7275, (2009).

[7] M. Minsky, Society of mind, p.^pp. 336: Simon and Schuster, (1988).

[8] R. C. Anderson, "Schema-Directed Processes in Language Comprehension," Cognitive Psychology and Instruction, A. M. Lesgold, J. W. Pellegrino, S. D. Fokkema and R. Glaser, eds., pp. 67-82, Boston, MA: Springer US, (1978).

[9] R. M. Gagné, The Conditions of Learning and Theory of Instruction, 4th ed.: Harcourt Brace, (1997).

[10] A. Bandura, Social Learning Theory, 1 ed., Englewood Cliffs, NJ: Prentice-hall, (1977).

[11] J. D. Novak, "Concept mapping: A useful tool for science education," Journal of Research in Science Teaching, 27, no. 10, pp. 937-949, (1990).

[12] M. D. Merrill, and D. Twitchell, Instructional design theory: Educational Technology, (1994).

[13] J. Scandura, "Role of rules in behavior: Toward an operational definition of what (rule) is learned," Psychological Review, 77, no. 6, pp. 516-533, (1970).

[14] J. R. Searle, "Is the brain a digital computer?." pp. 21-37, (1990) Published.

[15] V. Shute, and J. Psotka, Intelligent Tutoring Systems: Past, Present, and Future, Technical 
Paper, Human Resources Directorate Brooks Air Force Base, TX, USA, (1994).

[16] B. Inhelder, and J. Piaget, The early growth of logic in the child: Classification and seriation, UK: Routledge, (2013).

[17] L. S. Vygotsky, Mind in Society, Cambridge, MA: MIT Press, (1978).

[18] E. Wenger, Communities of practice: Learning, meaning, and identity: Cambridge university press, (1998).

[19] J. S. Bruner, "The act of discovery," Harvard Educational Review, 31, pp. 21-32, (1961).

[20] J. L. Kolodner, "Educational implications of analogy: A view from case-based reasoning," American psychologist, 52, no. 1, pp. 57-66, (1997).

[21] T. De Jong, and W. R. Van Joolingen, "Scientific Discovery Learning with Computer Simulations of Conceptual Domains," Review of Educational Research, 68, no. 2, pp. 179-201, (1998).

[22] D. H. Jonassen, "Thinking technology: Toward a constructivist design model," Educational technology, 34, no. 4, pp. 34-37, (1994).

[23] W. Feurzeig, S. Papert, M. Bloom, R. Grant, and C. Solomon, "Programming-languages as a conceptual framework for teaching mathematics," ACM SIGCUE Outlook, 4, no. 2, pp. 13-17, (1970).

[24] R. Duhrkopf, "HyperCard as a tool for educational software development," The American Biology Teacher, 50, no. 2, pp. 121122, (1988).

[25] M. Scardamalia, C. Bereiter, R. S. McLean, J. Swallow, and E. Woodruff, "Computersupported intentional learning environments," Journal of educational computing research, 5, no. 1, pp. 51-68, (1989).

[26] G. Siemens, "Connectivism: A Learning Theory for the Digital Age," International Journal of Instructional Technology \& Distance Learning, 2, http://www.itdl.org/Journal/Jan 05/article01. htm, (2005)].

[27] R. Kop, and A. Hill, "Connectivism: Learning Theory of the Future or Vestige of the Past?," International Review of Research in Open and Distance Learning, 9, no. 3, pp. 1-13, (2008).

[28] G. o. Japan, First Report of the National Council on Educational Reform (Rinkyoshin Dayori), The National Council on Educational Reform, Tokyo, Japan, (1985).

[29] G. o. Japan, Second Report of the National Council on Educational Reform (Rinkyoshin Dayori), The National Council, Tokyo, Japan, (1986).
[30] G. o. Japan, Basic Act on the Formation of an Advanced Information and Telecommunications Network Society IT Strategy Headquarters, (2001).

[31] I. S. Headquarters, e-Japan Strategy 2001, Strategic Headquarters for the Promotion of an Advanced Information and Telecommunications Network Society (IT Strategic Headquarters) Tokyo, Japan, (2001).

[32] I. S. Headquarters, e-Japan Strategy II 2003, Strategic Headquarters for the Promotion of an Advanced Information and Telecommunications Network Society (IT Strategic Headquarters) Tokyo, Japan, (2003).

[33] I. S. Headquarters, Priority Policy Program 2006 Strategic Headquarters for the Promotion of an Advanced Information and Telecommunications Network Society (IT Strategic Headquarters) Tokyo, Japan, (2006).

[34] I. S. Headquarters, I-Japan strategy 2015: Striving to create a citizen-driven, reassuring \& vibrant digital society, Strategic Headquarters for the Promotion of an Advanced Information and Telecommunications Network Society (IT Strategic Headquarters) Tokyo, Japan, (2009).

[35] K. Oshima, and Y. Muramatsu, "Current situation and issues related to ICT utilization in primary and secondary education," Fujitsu Scientific \& Technical Journal, 51, no. 1, pp. 3-8, (2015).

[36] G. o. Japan, Information and Communications in Japan 2009, Ministry of Internal Affairs and Communications, Tokyo, Japan, (2009).

[37] S. Baller, S. Dutta, and B. Lanvin, Global information technology report 2016, 978-1944835-03-3, World Economic Forum, Geneva, (2016).

[38] M. Funamori, "The Issues Japanese Higher Education Face in the Digital Age-Are Japanese Universities to Blame for the Slow Progress towards an Informationbased Society," International Journal of Institutional Research and Management, 1, no. 1, pp. 37-51, March 31, 2017, (2017).

[39] F. Blin, and M. Munro, "Why hasn't technology disrupted academics' teaching practices? Understanding resistance to change through the lens of activity theory," Computers \& Education, 50, no. 2, pp. 475-490, (2008).

[40] A. Kukulska-Hulme, J. Pettit, L. Bradley, A. A. Carvalho, A. Herrington, D. M. Kennedy, and A. Walker, "Mature Students Using Mobile Devices in Life and Learning," International Journal of Mobile and Blended Learning, 3, no. 1, pp. 18-52, (2011). 
[41] M. Cinque, "The "Reflective Student": The use of Mobile Devices Through Seamless Educational Spaces and Authentic Learning Scenarios," Handbook of Mobile Education, Z. L. Berge and L. Muilenburg, eds., pp. 209-223, New York, NY: Routledge, (2013).

[42] P. Ilic, "The Relationship between Students, Mobile Phones and Their Homework," Mobile as a Mainstream - Towards Future Challenges in Mobile Learning, Communications in Computer and Information Science M. Kalz, Y. Bayyurt and M. Specht, eds., pp. 146-155: Springer International Publishing, (2014).

[43] E. Hutchins, Cognition in the Wild: MIT press, (1995).

[44] S.-L. Wang, and P.-Y. Wu, "The role of feedback and self-efficacy on web-based learning: The social cognitive perspective," Computers \& Education, 51, no. 4, pp. 1589-1598, (2008).

[45] J. E. Rodriguez, "Social media use in higher education: Key areas to consider for educators," Journal of Online learning and Teaching, 7, no. 4, pp. 539-550, (2011).

[46] M. Balakrishnan, I. Mohomed, and V. Ramasubramanian, "Where's that phone?: geolocating IP addresses on 3G networks." pp. 294-300, (2009) Published.

[47] J. Knobbout, and E. Van Der Stappen, "Where is the Learning in Learning Analytics? A Systematic Literature Review on the Operationalization of Learning-Related Constructs in the Evaluation of Learning Analytics Interventions," IEEE Transactions on Learning Technologies, 13, no. 3, pp. 631-645, (2020).

[48] R. Guillot, J. Seanosky, I. Guillot, D. Boulanger, C. Guillot, V. Kumar, and S. N. Fraser, "Assessing Learning Analytics Systems Impact by Summative Measures." pp. 188-190, (2018) Published.

[49] E. Wood, J. Mueller, T. Willoughby, J. Specht, and T. Deyoung, 'Teachers' perceptions: Barriers and supports to using technology in the classroom," Education, Communication \& Information, 5, no. 2, pp. 183-206, (2005).

[50] K. A. Bingimlas, "Barriers to the Successful Integration of ICT in Teaching and Learning Environments: A Review of the Literature," Volume 5, Issue Number 3, 5, no. 3, pp. 235-245, (2009).

[51] S. Al-Senaidi, L. Lin, and J. Poirot, "Barriers to adopting technology for teaching and learning in Oman," Computers \& Education, 53, no. 3, pp. 575-590, 2009/11/01/, (2009).
[52] J. W. Richardson, "Challenges of Adopting the Use of Technology in Less Developed Countries: The Case of Cambodia," Comparative Education Review, 55, no. 1, pp. 8-29, (2011).

[53] P. A. Ertmer, "Addressing first- and secondorder barriers to change: Strategies for technology integration," Educational Technology Research and Development, 47, no. 4, pp. 47-61, 1999/12/01, (1999).

[54] A. Jones, $A$ review of the research literature on barriers to the uptake of ICT by teachers, British Educational Communications and Technology Agency (BECTA), (2004).

[55] J. Copley, and J. Ziviani, "Barriers to the use of assistive technology for children with multiple disabilities," Occupational Therapy International, 11, no. 4, pp. 229-243, (2004).

[56] L. Ilomäki, "Does Gender Have a Role in ICT Among Finnish Teachers and Students?," Scandinavian Journal of Educational Research, 55, no. 3, pp. 325-340, 2011/06/01, (2011).

[57] H. Salehi, and Z. Salehi, "Challenges for using ICT in education: teachers' insights," International Journal of e-Education, e-Business, $e$ Management and e-Learning, 2, no. 1, pp. 40-43, (2012).

[58] W. J. Pelgrum, "Obstacles to the integration of ICT in education: results from a worldwide educational assessment," Computers \& Education, 37, no. 2, pp. 163-178, 2001/09/01/, (2001).

[59] C. Jayalath, U. Wickramasinghe, H. Kottage, and G. Somaratna, "Factors Influencing Orderly Transition to Online Deliveries during COVID19 Pandemic Impact," Asian Journal of Education and Social Studies, pp. 10-24, (2020).

[60] W. Veen, "The Role of Beliefs in the Use of Information Technology: implications for teacher education, or teaching the right thing at the right time," Journal of Information Technology for Teacher Education, 2, no. 2, pp. 139-153, 1993/01/01, (1993).

[61] E. Löfström, and A. Nevgi, "University teaching staffs' pedagogical awareness displayed through ICT-facilitated teaching," Interactive Learning Environments, 16, no. 2, pp. 101-116, (2008).

[62] M. Deriquito, and Z. Domingo, Mobile learning for Teachers in Asia, 2227-5029, United Nations Educational, Scientific and Cultural Organization (UNESCO) Paris, France, (2012).

[63] J. Gikas, and M. M. Grant, "Mobile Computing Devices in Higher Education: Student Perspectives on Learning with Cellphones, 
Smartphones \& Social Media," The Internet and Higher Education, 19, pp. 18-26, (2013).

[64] F. M. Ihmeideh, "Barriers to the use of technology in Jordanian pre-school settings," Technology, Pedagogy and Education, 18, no. 3, pp. 325-341, 2009/10/01, (2009).

[65] D. A. Georgina, and C. C. Hosford, "Higher education faculty perceptions on technology integration and training," Teaching and Teacher Education, 25, no. 5, pp. 690-696, (2009).

[66] M. M. T. Rodrigo, "Quantifying the divide: a comparison of ICT usage of schools in Metro Manila and IEA-surveyed countries," International Journal of Educational Development, 25, no. 1, pp. 53-68, 2005/01/01/, (2005).

[67] K. Nikolopoulou, and V. Gialamas, "Barriers to the integration of computers in early childhood settings: Teachers' perceptions," Education and Information Technologies, 20, no. 2, pp. 285-301, 2015/06/01, (2015).

[68] W. Han, "Benefits and barriers of computer assisted language learning and teaching," USChina Foreign Language, 6, no. 9, pp. 40-43, (2008).

[69] E. Neyland, "Integrating online learning in NSW secondary schools: Three schools' perspectives on ICT adoption," Educational Technology, 27, no. 1, pp. 152-173, (2011).

[70] D. Galanouli, C. Murphy, and J. Gardner, "Teachers' perceptions of the effectiveness of ICT-competence training," Computers \& Education, 43, no. 1, pp. 63-79, 2004/08/01/, (2004).

[71] D. L. Butler, and M. Sellbom, "Barriers to adopting technology," Educause Quarterly, 2, no. 1, pp. 22-28, (2002).

[72] M. M. Groves, and P. C. Zemel, "Instructional Technology Adoption in Higher Education: An Action Research Case Study," International Journal of Instructional Media, 27, no. 1, pp. 5765, (2000).

[73] K. Mossberger, C. J. Tolbert, and A. Hamilton, "Measuring Digital Citizenship: Mobile Access and Broadband," International Journal of Communication, 6, pp. 2492-2528, (2012).

[74] K. Tosh, S. Doan, A. Woo, and D. Henry, Digital Instructional Materials: What Are Teachers Using and What Barriers Exist?, (2020).

[75] Y. Liu, S. Han, and H. Li, "Understanding the factors driving m-learning adoption: a literature review," Campus-Wide Information Systems, 27, no. 4 , pp. 210-226, (2010).
[76] N. Gandelman, and R. Hernández-Murillo, "Risk aversion at the country level," (2015).

[77] B. H. Hall, and B. Khan, Adoption of new technology, National bureau of economic research, (2003). 